\title{
Evidence for white matter abnormalities in schizophrenia
}

\section{Citation}

Kubicki, Marek, Robert W McCarley, and Martha E Shenton. 2005. “Evidence for White Matter Abnormalities in Schizophrenia." Current Opinion in Psychiatry 18 (2) (March): 121-134. doi:10.1097/00001504-200503000-00004.

\section{Published Version}

doi:10.1097/00001504-200503000-00004

\section{Permanent link}

http://nrs.harvard.edu/urn-3:HUL.InstRepos:28627100

\section{Terms of Use}

This article was downloaded from Harvard University's DASH repository, and is made available under the terms and conditions applicable to Other Posted Material, as set forth at http:// nrs.harvard.edu/urn-3:HUL.InstRepos:dash.current.terms-of-use\#LAA

\section{Share Your Story}

The Harvard community has made this article openly available.

Please share how this access benefits you. Submit a story.

\section{Accessibility}


Published in final edited form as:

Curr Opin Psychiatry. 2005 March ; 18(2): 121-134.

\title{
Evidence for white matter abnormalities in schizophrenia
}

\author{
Marek Kubickia,b, Robert W. McCarley ${ }^{a}$, and Martha E. Shenton ${ }^{a, b}$ \\ aVA Boston Healthcare System, Clinical Neuroscience Division, Laboratory of Neuroscience, \\ Department of Psychiatry, Harvard Medical School, Brockton, Massachusetts, USA \\ bSurgical Planning Laboratory, MRI Division, Department of Radiology, Brigham and Women's \\ Hospital, Harvard Medical School, Boston, Massachusetts, USA
}

\begin{abstract}
Purpose of review-The purpose of this review is to highlight important recent imaging, histological, and genetic findings relevant to white matter abnormalities in schizophrenia. It is cast within the context of research findings conducted over the last 5 years, where we analyze their importance in understanding schizophrenia, as well as discuss future directions for research.

Recent findings-White matter abnormalities have long been hypothesized in schizophrenia, although only recently has it become possible to investigate them more closely. This has come about as a result of advances in neuroimaging, including new imaging techniques sensitive to white matter structure, as well as advances in computer science, with new analysis techniques making it possible to evaluate several interconnected brain regions at a time. Postmortem studies, with advances such as fluoroscopy and electron microscopy, have also led to quantifying populations of different brain cells, including myelin-forming oligodendrocytes. Moreover, molecular studies enable examination of immunoreactivity of proteins that are responsible for building myelin sheaths. Additionally, microarray genetic studies allow us to investigate myelin-related genes in schizophrenia. Taken together, these technological advances bring us closer to understanding white matter pathology in schizophrenia.
\end{abstract}

Summary-Advances in new imaging techniques likely account for the renewed interest in investigating white matter abnormalities in schizophrenia, with over 30 new articles published on this topic in the last 12 months, compared with 11 the year before. We review recent imaging, histological, and genetic findings that suggest white matter abnormalities in schizophrenia.

\section{Keywords}

brain abnormalities; diffusion tensor imaging; fractional anisotropy; interstitial neurons; magnetic resonance imaging; magnetic transfer imaging; myelin; oligodendrocytes; schizophrenia; white matter

\section{Introduction}

Research findings in schizophrenia largely confirm structural brain abnormalities, which are present in a large number of brain regions, some of which are disparate in terms of proximity, but are nonetheless highly functionally related (see review in [1]). The notion, however, that schizophrenia is a disorder characterized by abnormal frontal and temporal connections has its

\footnotetext{
(C) 2005 Lippincott Williams \& Wilkins

Correspondence to Dr Martha Shenton MD PhD, Department of Psychiatry-116A, VA Boston Healthcare System - Brockton Division, Harvard Medical School, 940 Belmont Street, Brockton, MA 02301, USA Tel: +1 5085834500 ext 1371, 2473; fax: +1 5085800059 ; martha_shenton@hms.harvard.edu.
} 
historical roots in the beginning of the last century, when Wernicke [2] and Kraepelin [3] suggested the importance of fronto-temporal connections in the neuropathology of schizophrenia. This hypothesis reemerged more recently, with new brain investigations involving various imaging methods [4-8].

These studies and others have led to magnetic resonance imaging (MRI) structural findings of gray matter abnormalities in schizophrenia, although there has been no compelling postmortem evidence to suggest a concomitant neuronal loss in these brain regions. Instead, abnormalities of neuronal cytoarchitecture have been found in microscopic postmortem investigations in schizophrenia. These abnormalities include a reduction in neuronal size, dendritic spine density, dendritic length, and in synaptic proteins (for a review, see Harrison [9]). Moreover, neuropathological studies suggest that astrocytes and oligodendrocytes, glial cells involved in signal conduction and cell metabolism [10], may be abnormal in schizophrenia [11]. Since glial cells also play an important role in neuronal migration and in synaptic function (including glutamatergic and N-methyl-o-aspartate regulation), their dysfunction could lead to abnormalities observed in schizophrenia, such as reduced neuronal size, reduced levels of synaptic proteins, as well as abnormalities in neurotransmission and functional disconnectivity. Of further note, genetic studies [12] also point to oligodendrocyte abnormalities in schizophrenia.

Recently, in-vivo magnetic resonance methods have been introduced which are sensitive to white matter organization and may be useful in investigating abnormalities in schizophrenia. Specifically, diffusion tensor imaging (DTI), an indicator of the coherence, organization and density of the fibers within the white matter fiber bundles, has been applied to several investigations of schizophrenia, in which both disseminated as well as focal white matter abnormalities have been reported (for a review, see $\left[13,14^{* *}\right]$ ). Magnetization transfer imaging, another new MRI technique believed to be sensitive to axonal and myelin integrity [15], has been used to investigate white matter lesions in multiple sclerosis, increasing both the sensitivity and specificity of white matter MRI findings. This technique has also been applied to schizophrenia to describe white matter abnormalities [16,17].

Structural MRI studies, which have thus far shown mainly negative findings for white matter (see review in [1]), have benefited from new advances in both imaging and image processing analyses. Voxel-based morphometry (VBM), a technique that affords an opportunity to test for magnetic resonance intensity differences between groups of individuals in multiple regions of the brain without a priori hypothesis [18], has also been applied to the study of white matter in schizophrenia. This technique has been shown to be more sensitive to white matter structural abnormalities than traditional investigations based on structural MRI measurements of white matter volume $[19,20]$.

What these new tools have in common is that they provide converging evidence for white matter pathology in schizophrenia. Since white matter pathology is not easily discerned (i.e. MRI clinical readings of schizophrenia scans are mostly negative, there are no reports of gliosis in the brains of patients diagnosed with schizophrenia, and neuronal loss, if any, is also questionable), the combination of multiple techniques, along with a better understanding of both their advantages as well as their limitations, is necessary to understand further the neuropathology behind this devastating disease. Below, we review the most recent white matter abnormality findings in schizophrenia, published between 1 January 2003 and August 2004. Studies have been selected using PubMed and Medline, using the key words white matter and schizophrenia. 


\section{Structural white matter abnormalities in schizophrenia}

As mentioned previously, magnetic resonance structural imaging studies of white matter in schizophrenia have thus far not been very informative. Only a small number of MRI studies have evaluated white matter volume differences between patients with schizophrenia and controls, and these findings have been largely negative [21,22] (see also review in [1]). A study by Wible and coworkers [22], however, reported correlations between white matter volume and temporal lobe volume reduction (i.e. superior temporal gyrus, amygdala-hippocampal complex, and parahippocampal gyrus), suggesting a possible relationship between white and gray matter pathology. Moreover, in one of the few studies reporting white matter volume reduction in schizophrenia, Breier and coworkers [23] noted a similar correlation between prefrontal white matter reduction and amygdala-hippocampal complex volume reduction. More recently, studies using VBM analyses have shown white matter abnormalities in both temporal and frontal lobe regions [19], and bilaterally in the frontal lobe [20].

Thirteen studies published over the past year on structural white matter abnormalities in schizophrenia have used three different strategies: whole white matter volumes, regional white matter volumes, and VBM. More specifically, two studies have investigated whole white matter volumes, thus providing evidence concerning general processes that may occur in schizophrenia. In contrast, eight studies have investigated regional white matter volume changes, whereby whole white matter is divided into lobar segments. Finally, three studies have used VBM analyses to search for localized, focal changes within the white matter in schizophrenia (see Table 1).

\section{Whole white matter}

Studies that evaluate whole white matter volumes generally involve automated brain segmentation, which, although not sensitive to local anatomical abnormalities, may be an indicator of the general processes taking place in the white matter (see Fig. 1 for an example of the segmentation). Christensen et al. [25*0], for example, reported a decrease in total white matter volume in 13 patients diagnosed with schizophrenia, following 4 weeks of successful neuroleptic medication (success defined by a reduction in positive symptom scores). These authors suggested that excitotoxicity-induced myelin swelling causes functional and anatomical disconnectivity (manifesting as psychosis exacerbation), which remits after successful treatment, thus accounting for a reduction in white matter volume.

The notion that clinical symptoms in schizophrenia may be related to an acute inflammatory process is interesting, and has also been suggested in multiple sclerosis and metachromatic leukodystrophy studies, in which inflammation and demyelination are the primary pathological processes observed. Moreover, investigators have been impressed by the similarities observed between patients diagnosed with schizophrenia and patients diagnosed with metachromatic leukodystrophy [37]. The early symptoms observed in this disorder are so similar to schizophrenia that these patients are often misdiagnosed with schizophrenia. The symptoms include delusions, hallucinations, and cognitive disruptions, all hallmark symptoms of schizophrenia. Of further interest here, a demyelinating process in schizophrenia has also been suggested by several postmortem studies (discussed below).

Studying white matter abnormalities in schizophrenia also affords an opportunity to investigate possible demyelination/degenerative processing taking place in the central nervous system, as well as to examine white matter abnormalities in the context of a genetic predisposition to developing schizophrenia. This focus fits in nicely with the notion that schizophrenia is a disorder of neurodegenerative processes or of neurodevelopmental origin, though the two are not mutually exclusive (see review in [1]). Relevant here is the second study to use whole white matter volume measurements, by Hulshoff Pol and coworkers [24], who evaluated gray and 
white matter in 11 monozygotic and 11 same-gender dizygotic twins discordant for schizophrenia, in comparison with 11 monozygotic and 11 dizygotic healthy twins. These investigators reported white matter volume reductions in all twins discordant for schizophrenia, while gray matter volumes decreased only in patients. These authors concluded that white matter volume reflects the increased genetic risk to developing schizophrenia, while gray matter volumes are more likely associated with environmental factors.

\section{Region of interest approach to evaluating local white matter}

Eight additional papers published last year used a hypothesis-driven region of interest (ROI) approach. This technique can be either manual, which involves manual tracing of small brain regions, semiautomatic, involving manual division of automatically derived white matter maps, or fully automatic, when software is used to detect and segment regions of the brain based on atlas registration.

Mitelman and coworkers [29] used automatically segmented frontal, temporal and occipital white matter regions in patients diagnosed with schizophrenia who had good versus poor outcome, and found that white matter volume in temporal and occipital lobe, but not prefrontal lobe, were associated with poor outcome. Moreover, additional volume loss was observed for patients, compared with controls, regardless of outcome, although white matter volume was decreased primarily in the occipital region. However, in a similar study by Milev et al. [34], white matter in prefrontal and temporal regions was measured, and no relationship was found between 5-year outcome and volumes in any of the brain regions evaluated. Ho and coworkers [32] evaluated the relationship between frontal, temporal, parietal and occipital white matter volumes and duration of untreated psychosis, and they did not find any significant correlations between these two factors. These investigators also reported no relationship between medication and prefrontal white matter volumes. Moreover, a study by Arango et al. [35] investigated prefrontal white matter before and after a 10-week period of treatment with clonazepine (22 patients) and haloperidol (23 patients), and found no relationship between medication dosage and white matter volume changes. These latter findings are thus not consistent with the aforementioned whole white matter volume changes observed in patients with schizophrenia in response to medical treatment [25*]. Methodological differences could be one possible explanation for these discrepancies.

Another ROI study this past year $\left[33^{\circ}\right]$ investigated the relationship between progressive reduction of white matter volume in schizophrenia and clinical symptoms, and demonstrated that negative symptoms were correlated with frontal lobe volume reduction. Mathalon and coworkers [31] focused on degenerative processes of white matter in patients with schizophrenia comorbid for alcoholism, and found, although statistically nonsignificant, additional white matter volume reduction in prefrontal white matter in the comorbid sample.

In addition to the whole white matter study discussed above by Hulschoff Pol et al. [24], there have been two ROI studies that have investigated evidence for a developmental origin of white matter changes. The first is a study by Bartzokis and colleagues [30 $]$ who demonstrated an association between white-to-gray matter ratios and age in controls, and the lack thereof in patients with schizophrenia. This finding was interpreted as suggesting that the adult developmental process associated with white matter maturation and myelination is dysregulated in schizophrenia. The second study, by Highley and colleagues [36], evaluated white matter volume and an index of gyrification in 61 patients with schizophrenia and 42 controls. White matter was divided into frontal, temporal, and parieto-occipital white matter. Findings showed that occipito-parietal white matter volumes decreased in females with schizophrenia and increased in males with schizophrenia, compared with controls, suggesting that the changes in connectivity underlying the pathogenesis of schizophrenia are gender specific and are expressed in occipito-parietal white matter. 


\section{Voxel-based morphometry analyses of white matter}

Finally, within the last year, three VBM studies have focused on white matter abnormalities in schizophrenia. VBM is a new image analysis technique that has become very popular in recent years. Its popularity is primarily due to the fact that it is an automated procedure that can be used to investigate multiple brain regions at the same time, and is therefore much less time consuming than the traditional ROI approach. Due to its automation, the method is also statistically much more powerful, as very large cohorts can be easily compared.

Using VBM, and then confirmed with manual ROI analyses, Zhou and coworkers [28] reported decreased volume and increased asymmetry of the anterior limb of the internal capsule in 53 patients diagnosed with chronic schizophrenia compared with 48 controls. In a separate study

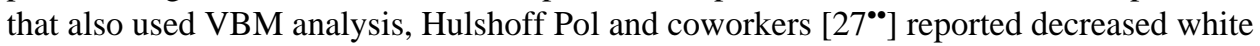
matter density within the corpus callosum, right anterior limb of the internal capsule, and anterior commissure in a cohort of 159 patients diagnosed with schizophrenia compared with 158 controls. In addition, Spalletta and coworkers [26] reported white matter density reductions in arcuate fasciculus, uncinate fasciculus, cortico-striatal fibers and fronto-temporal fibers in a cohort of 28 patients diagnosed with chronic schizophrenia, when compared with 28 matched controls.

\section{Summary}

MRI structural white matter findings in schizophrenia over the last year are generally in agreement with previous investigations. Multiple brain regions appear to be affected in schizophrenia, although rather than generalized deficits, these abnormalities appear to be localized predominantly in temporal and frontal white matter. We note also the increase in use of new methodological advances, such as VBM, which offer a quick way to evaluate multiple white matter regions across many patients, in contrast to the usual labor-intensive manual tracing of brain regions of interest. As a result of improvements in analysis techniques, white matter changes in schizophrenia are also better anatomically localized, and findings, similar to some DTI studies (reviewed below), point to the likely importance of frontal-temporal connections (i.e. uncinate fasciculus, arcuate fasciculus, internal capsule, cingulum bundle), as well as interhemispheric connections (i.e. corpus callosum, anterior commissure) in the neuropathology of schizophrenia. Additionally, medication effects have been observed over a short period of time (4 weeks), suggesting that myelin inflammatory processes may be going on during psychosis exacerbation. Finally, another interesting observation comes from work published this past year by Bartzokis and coworkers [ $\left.30^{\circ}\right]$, who documented differences in the maturation of white matter processes (myelination) between patients diagnosed with schizophrenia and normal controls, which could underlie a predisposed vulnerability for some individuals to develop schizophrenia [38]. Only more careful, longitudinal studies of schizophrenia, however, will be able to address the question of white matter changes over time.

\section{Diffusion tensor imaging studies in schizophrenia}

DTI has been increasingly popular since its introduction in 1994 [39]. This magnetic resonance in-vivo technique is based on detecting the motion of water molecules in the presence of directionally oriented magnetic gradients. Figure 2 shows an example of DTI. This imaging technique thus makes it possible to detect the direction and orientation of water diffusion in the brain, and is shown to be sensitive to detecting white matter fiber tract abnormalities in various brain pathologies, including brain tumors, ischemia, multiple sclerosis, alcoholism, Alzheimer's disease, and so on (for a review, see $\left[13,14^{* *}\right]$ ). Fractional anisotropy, a quantitative index of white matter coherence and integrity, is the most frequently used measure to evaluate water diffusion in white matter. Schizophrenia studies, thus far, have demonstrated abnormalities in multiple white matter regions, including the corpus callosum [40,41], the 
uncinate fasciculus [42], prefrontal and temporal white matter [43,44], as well as abnormalities in the internal capsule [43].

This year alone, 11 additional studies have used DTI to investigate white matter abnormalities in schizophrenia (Table 2). The popularity of DTI is understandable, since this technique affords the unique opportunity to visualize and to quantify white matter fiber bundles, something not possible even a decade ago. Studies published in the last year have evaluated white matter fiber tracts, namely superior and middle cerebellar peduncles [45], cingulate bundle [46], uncinate fasciculus $\left[47^{\circ}\right]$, arcuate fasciculus [47 $]$, and corpus callosum [46,48]. In addition, nonspecific, larger areas of prefrontal, occipital, temporal and parietal white matter have also been studied $[45,46,49]$. Finally, VBM analyses, an increasingly popular method to analyze whole white matter without a priori hypothesis, have been applied to maps of fractional anisotropy in patients with schizophrenia and in controls $\left[47^{\bullet}, 50,51^{\circ *}, 52^{\circ *}\right]$. DTI has also been used to look at white matter asymmetry in schizophrenia, an important issue, particularly in light of the emphasis placed on neurodevelopmental abnormalities in schizophrenia.

More specifically, cerebellar connections have been evaluated in two studies in schizophrenia published last year, with conflicting results. Okugawa and colleagues [55] reported middle cerebellar peduncle abnormalities in a group of 25 patients with schizophrenia, when compared with 21 healthy controls (along with its relationship to the dosage of medication). However, Wang and colleagues [45] evaluated 29 patients with schizophrenia and 20 controls, and reported no differences in either middle, or superior cerebellar peduncles. Different resolution, as well as different planes used (axial versus sagittal), may account for these differences. Two additional ROI studies found no differences in the corpus callosum in patients with schizophrenia compared with controls [46,48] (so far the most consistent finding in DTI schizophrenia research), while one study did [50], and one study did not find differences between groups for the internal capsule [46]. Two studies found abnormalities in the cingulum bundle $\left[14^{\bullet *}, 46\right]$.

Prefrontal, temporal, parietal and occipital white matter regions have been parcellated and evaluated in two separate studies $\left[46,53^{\circ}\right]$, and while one study reported group differences in all these regions [53"], the other reported no differences in any of these regions [46]. In addition, one study [49] investigated white matter within the prefrontal cortex in schizophrenia (no control group was included), and found correlations between decreased fractional anisotropy and increased negative symptoms.

VBM analyses have also been applied to diffusion tenor images and used to compare patients diagnosed with schizophrenia with controls. There have been three such studies over the last year. The first is a study by Burns and coworkers $\left[47^{\circ}\right]$ who reported decreased fractional anisotropy in uncinate fasciculus, arcuate fasciculus, but not in cingulate fasciculus in patients with schizophrenia compared with controls. The second study by Ardekani and coworkers [50] reported a reduction of fractional anisotropy in patients with schizophrenia in the corpus callosum, as well as in frontal, parietal, occipital and temporal white matter. Finally, the third study by Hubl and coworkers [51*0] reported fractional anisotropy reduction in schizophrenia in the uncinate fasciculus, arcuate fasciculus, inferior longitudinal fasciculus, and in the corpus callosum.

Of further note, when patients with schizophrenia are divided into those with and those without auditory hallucinations, patients with auditory hallucinations have higher fractional anisotropy in the arcuate fasciculus, cingulum bundle and in the corpus callosum compared with patients without auditory hallucinations [ $51^{\circ}$ ] $]$. Also those patients with hallucinations, when compared with controls, had higher fractional anisotropy values in the arcuate fasciculus and corpus callosum. This is thus far the only study that has shown an increase in diffusion anisotropy in 
schizophrenia. The authors speculated that an increase in fractional anisotropy in the arcuate fasciculus may be associated with an overactivation of regions associated with language in patients with hallucinations.

Another very interesting study published over the last year [52*0] is a study published by our laboratory that evaluated the asymmetry of white matter fiber tracts in schizophrenia patients compared with controls. This study also used VBM analyses, although unlike other studies it utilized a high-order co-registration method that registers brains to the template on the basis of directional information extracted from diffusion images, and thus is more precise in registration than the traditional VBM methods. This study reported asymmetry in controls in the corpus callosum, cingulate bundle, optic radiation, superior cerebellar peduncle, the anterior limb of the internal capsule, the uncinate fasciculus, and in the superior longitudinal fasciculus. This asymmetry was either decreased or diminished in schizophrenia patients. The authors suggested that their findings support a neurodevelopmental origin for schizophrenia.

\section{Summary}

DTI findings in schizophrenia over the last year provide further evidence for white matter abnormalities in schizophrenia. The results, however, are often conflicting. While some studies published this year confirm previous findings, some contradict them. One possible reason for the discrepancies reported in DTI studies may be that the resolution of today's diffusion scans is low, compared with structural MRI, and the noise is high. Another possible reason is that unlike the structural MRI research, where ROI analysis is the gold standard, and every new method can be tested against this gold standard, in DTI research at this time there is no such standard. Finally, another possible reason for inconsistent findings is the significant methodological differences among DTI studies. Further research is needed to address these issues, including the development of better acquisition sequences so as to increase resolution, and better post-processing tools, in order to take full advantage of the diffusion phenomenon.

\section{Other magnetic resonance imaging studies in schizophrenia}

Another MR technique that is sensitive to axonal and myelin density, and enables the detection of abnormalities in white matter structure, is magnetization transfer imaging. This imaging technique provides an index of axonal/myelin density, called magnetization transfer ratio (MTR) (see an example in Fig. 3). This method has been used previously in two publications $[15,56]$ in which gray matter, but not white matter changes in schizophrenia patients were observed. This year, however, Bagary and coworkers [17] used MTR to evaluate patients with schizophrenia and controls and showed that the uncinate fasciculus axonal density/myelin density in schizophrenia is smaller than that observed in controls. This finding is consistent with two diffusion studies in schizophrenia discussed above $\left[42,47^{\circ}\right]$, and further suggests a disruption of anatomical connectivity between the frontal and temporal lobes, as this fiber connects temporal pole and orbital frontal cortex.

Finally, this past year, T2 relaxation analysis, sensitive to the fraction of water bonded to myelin, was applied to schizophrenia in order to investigate white matter myelin abnormalities in both first episode and chronic samples [57*0]. Interestingly, the results of the Flynn et al. study also confirm the results of the Ho et al. [33"] structural study discussed above, which showed that in controls, but not in patients with schizophrenia, both myelin water fraction in whole white matter, as well as in prefrontal white matter, increased with age, thus demonstrating ongoing maturation/myelination, at least in controls. 


\section{Summary}

MTR and T2 relaxation analysis provide evidence for white matter abnormalities in schizophrenia, thereby confirming some of the structural and DTI findings published in recent years. Neither of these two methods have been used frequently, although both show great potential, and both fully complement other methods, such as structural MRI and DTI, for investigating white matter abnormalities in schizophrenia, as well as for increasing the specificity of these findings.

\section{Histopathological studies in schizophrenia}

Until recently, there were only a small number of postmortem studies of white matter in schizophrenia, and these findings, similar to the MRI findings, were inconclusive. Specifically, two earlier studies reported decreased fiber number and density in the anterior commissure and the corpus callosum in women but not in men with schizophrenia [58,59], and no differences in the number and density of fibers in the uncinate fasciculus [60].

Of further note, there is growing evidence to suggest that glial cells, particularly oligodendrocytes, are abnormal in schizophrenia [11,12]. The Uranova et al. [11] study reported an abnormal expression of myelin-related genes in schizophrenia. The Hakak et al. [12] study, using electron microscopy, showed both qualitative and quantitative abnormalities in postmortem brains of patients with schizophrenia in the oligodendroglia in the prefrontal cortex and caudate nucleus, including a marked increase in the density of concentric lamellar bodies (indicating damage to myelinated fibers) in the caudate nucleus of schizophrenic brains. Importantly, if glial dysfunction is confirmed in schizophrenia, this alone could explain abnormal neuronal cytoarchitecture and functional deficits including fronto-temporal disconnections observed in schizophrenia (see also the recent review of white matter findings in schizophrenia by Davis et al. [61]).

As attention shifts gradually from gray to white matter pathology in schizophrenia, and since fronto-temporal abnormalities are among the most compelling findings in this disorder, it is not surprising that this year alone, nine new schizophrenia studies investigated frontal and temporal white matter in postmortem brains of patients with schizophrenia (see Table 3).

From the nine studies published last year that focused on white matter pathology, five investigated oligodendrocyte number, density, function, and distribution, three evaluated the distribution of neurons in white matter (interstitial cells), and one evaluated the length of fibers in whole white matter, as well as in the prefrontal cortex.

\section{Oligodendrocyte number, density, distribution and function}

With respect to the five studies investigating oligodendrocyte number, density, distribution, and function, this work followed earlier work by Uranova and colleagues [11], who found a reduction in number and size of oligodendrocytes in prefrontal and thalamic areas in schizophrenia. This past year, the same researchers evaluated oligodendrocyte density in layer VI of Brodmann area 9 of the prefrontal cortex and in adjacent white matter in schizophrenia [65]. The investigators found a significant decrease in numerical density of oligodendrocyte cells in gray, but not white matter in schizophrenia. Another study by Hof and coworkers [66 ], which investigated oligodendrocyte density and spatial distribution in layer III of Brodmann area 9 and gyral white matter in schizophrenia, found decreased oligodendrocyte number and density in both gray and white matter in patients with schizophrenia. The patients in this sample were, however, much older than in the Uranova et al. study (mean 77 versus 45 in Uranova study), which could account for the observed differences. 
Flynn and co-authors [57"*] investigated oligodendrocyte function in the anterior frontal cortex in schizophrenia. They measured two oligodendrocyte-associated proteins - cyclic nucleotide phosphodiesterase (CNP-ase), and myelin-associated glycoprotein (MAG). The results showed a decrease in immunoreactivity in both proteins in schizophrenia, compared with controls. Interestingly, these two proteins have also been described in a study by Hakak and coworkers [12], who reported lower levels of mRNA for genes related to these proteins. Finally, the two remaining studies that investigated oligodendrocyte function in schizophrenia focused on their relevance to a neurodevelopmental hypothesis. The first of these is a study by Tkachev et al. $\left[67^{\circ}\right]$ who evaluated the expression of oligodendrocyte and myelin-related genes in prefrontal cortex (mixture of gray and white matter) in schizophrenia. Here, a microarray analysis of RNA in schizophrenia revealed decreased expression of genes related to oligodendrocyte lineage (basic loop helix protein, OLIG2; high mobility group protein, SOX10), oligodendrocyte growth and differentiation (neuregulin receptor, ERBB3; transferin), and mature myelinating oligodendrocyte function (MAG; proteolipid protein 1, PLP1; myelin protein zero, MPZL1; oligodendrocytespecific protein, CLDN11; myelin oligodendrocyte protein, MOG) in schizophrenia.

The second of these studies was conducted by Aston et al. [68], and evaluated the expression of genes related to oligodendrocyte function, again using microarray RNA analysis, but this time in middle temporal gyrus in schizophrenia. Results from this study also showed a significant decrease in the expression of myelination-related genes, namely MAG, plasmolipin (PLLP), PLP1, ERBB3. In addition, these investigators also reported a decreased expression of genes regulating neurodevelopment (i.e. tumor necrosis factor receptor-associated factor 4, TRAF4; basic helix-loop-helix protein, Neurodi; histonedeacetylase 3).

\section{The distribution of neurons in white matter}

The remaining three studies published last year focused on interstitial neurons, neurons of unclear function that can be found in small quantities in white matter. The abnormal distribution of interstitial white matter neurons (IWMNs) in schizophrenia is thought to provide support for the neurodevelopmental hypothesis of schizophrenia. It has been previously found that these neurons, representing remnants of the cortical subplate, and involved in cortical development and in the guidance of neuronal migration, are abnormally distributed in schizophrenia. Studies published previously, for example, have found increased density of interstitial neurons in prefrontal, temporal $[70,71]$ and parietal lobe [72] white matter. This year, Eastwood and Harrison [62*0] documented increased density of IWMNs in superficial temporal white matter, which was not observed in deep white matter. In addition, the expression of reelin, a key developmental signaling molecule, was reported to be decreased in both superficial as well as deep white matter IWMNs in schizophrenia. Since interstitial neurons play a role in brain development, specifically in neuronal migration, thus indirectly involved in forming connections between brain regions, investigators interpreted their findings as supportive of neurodevelopmental theories of schizophrenia. In addition, since reelin is viewed as the key developmental signaling molecule, the observed relationship between density of interstitial neurons and reelin expression may contribute to the aberrant synaptic connectivity observed in schizophrenia.

Kirkpatrick and coworkers [63] also investigated IWMNs in schizophrenia, evaluating both deficit and nondeficit patients with schizophrenia. They found increased density of IWMNs in dorsolateral prefrontal cortex in the deficit group $(n=3)$ compared with the nondeficit $(n=4)$ as well as the control $(n=5)$ groups, suggestive of different pathophysiology for deficit and nondeficit schizophrenia (however, the deficit group was much older, which could also account for the differences). Finally, Rioux et al. [64], using the same staining method as Kirkpatrick (see Table 3 for methodological details), also found a maldistribution of IWMNs, especially 
in the deeper white matter of the parahippocampal gyrus in patients with schizophrenia compared with controls.

While abnormal density and function of oligodendrocytes, and maldistribution of interstitial white matter neurons in schizophrenia may suggest the involvement of white matter connections in the neuropathology of schizophrenia, the fibers interconnecting different brain regions have never been quantified in schizophrenia. The first study to evaluate interconnecting brain regions was conducted this year by Marner and Pakkenberg [69*0. A stereological method was used to quantify the length of myelinated nerve fibers in the whole brain, as well as in the prefrontal cortex, and no group differences were found.

\section{Summary}

Postmortem white matter findings in schizophrenia published over the last year, similar to other methods discussed, are in agreement with previous investigations. Oligodendrocyte function, as well as their density and distribution, seem to be affected in schizophrenia. The same can be said of the density and distribution of interstitial neurons located in white matter. While these factors can contribute to decreased connectivity and disconnection syndromes observed in this disorder, the organization and thickness of the fibers, rather than their number, seem to be affected.

\section{Future directions for the investigation of white matter abnormalities in schizophrenia}

With the advent of technological advances in both in-vitro postmortem as well as in-vivo MRI methods, we are just beginning to understand more fully the role that white matter pathology plays in schizophrenia. Hypotheses regarding connectivity abnormalities in schizophrenia can now be approached empirically, as for example the evaluation of fronto-temporal connections such as the uncinate fasciculus, cingulum bundle, arcuate fasciculus, fornix, and so on. Not surprisingly, with new methods being developed almost every year, interest in white matter abnormalities in schizophrenia has grown exponentially. Some of these methods use already established techniques, and show consistent results (such as postmortem findings of oligodendrocyte and interstitial neuron function and density), while other methods are still in the developmental phase (such as genetic and diffusion methods).

What is clear, however, is that future schizophrenia studies investigating white matter abnormalities will need to combine multiple imaging techniques that highlight white matter pathologies, such as DTI, proton spectroscopy, magnetization transfer techniques and relaxation time measurements, with postmortem studies in order to both define microscopic pathologies observed in schizophrenia as well as to validate in-vivo methods. It is also important to understand further the relationship between MRI-derived measures and the organization of axons and myelin in white matter. In addition, closer examination of the relationship between age, gender, and medication, as well as other confounding variables, and white matter pathology, would enable us to understand more fully white matter changes in schizophrenia. Of note, improvements in MRI methodology will be needed to achieve more reproducible results in schizophrenia. Also, there are several new and exciting in-vivo technologies on the horizon, such as fiber tractography, where long fiber bundles can be followed from one part of the brain to another, which will likely also increase our understanding of the processes going on in white matter that affect brain connectivity and underlie schizophrenia symptoms (Fig. 4). Finally, such studies should be conducted in concert with functional MRI and positron emission tomography imaging in order to characterize and to understand more fully both functional and structural abnormalities in schizophrenia. An example of fiber tractography of the uncinate fasciculus, co-registered with a DTI fractional 
anisotropy coronal image, is displayed in Fig. 5, in which the neuroanatomical connections provided by the fiber tractography can be appreciated.

\section{Conclusion}

Schizophrenia is no longer viewed as a disorder characterized by gray matter abnormalities alone. Recent studies, reviewed here, provide strong evidence for a disruption of white matter integrity in schizophrenia. For example, the aging process, which involves white matter myelination/maturation, may be quite different in patients with schizophrenia compared with controls. Moreover, the distribution of white matter cells (oligodendrocytes and interstitial neurons) may also be abnormal in schizophrenia. These latter findings are supported by recent genetic studies, which provide evidence for abnormalities in myelin formation. Future studies need to follow up these intriguing findings as well as to develop further white matter tractography methods, based on DTI and MTR, that will likely aid in our ability to quantify specific white matter fiber connections that are disrupted in schizophrenia. More studies are also needed that highlight the role of white matter abnormalities in schizophrenia in the context of gray matter abnormalities and functional, clinical, and behavioral abnormalities, using functional and structural imaging as well as cognitive and behavioral probes.

\section{Acknowledgments}

This research was supported in part by the National Alliance for Research on Schizophrenia and Depression (MK), the National Institute of Mental Health (RO3 MH068464-01 to MK, K02 MH 01110 and R01 MH 50747 to MES, R01 MH 40799 to RWM), by the Veterans Administration Merit Awards (MES and RWM) and by a VA Research Enhancement Award Program (RWM and MES). The authors also wish to acknowledge Erin Connor for her assistance in getting the bibliography and tables together, and Marie Fairbanks for her administrative support.

\section{Abbreviations}

DTI, diffusion tensor imaging; IWMN, interstitial white matter neuron; MRI, magnetic resonance imaging; MTR, magnetization transfer ratio; ROI, region of interest; VBM, voxelbased morphometry.

\section{References and recommended reading}

Papers of particular interest, published within the annual period of review, have been highlighted as:

- of special interest

•• of outstanding interest

1. Shenton ME, Dickey CC, Frumin M, et al. A review of MRI findings in schizophrenia. Schizophr Res 2001;49:1-52. [PubMed: 11343862]

2. Wernicke, C. Grundrisse der Psychiatrie. Thieme; Leipzig: 1906.

3. Kraepelin, E. Dementia Praecox. Churchill Livingstone; New York: 19191971. Barclay SBE, translator

4. Weinberger DR, Berman KF, Suddath R, et al. Evidence of dysfunction of a prefrontal-limbic network in schizophrenia: a magnetic resonance imaging and regional cerebral blood flow study of discordant monozygotic twins. Am J Psychiatry 1992;149:890-897. [PubMed: 1609867]

5. Weinberger DR. Implications of normal brain development for the pathogenesis of schizophrenia. Arch Gen Psychiatry 1987;44:660-669. [PubMed: 3606332]

6. Weinberger DR. From neuropathology to neurodevelopment. Lancet 1995;346:552-557. [PubMed: 7544856]

7. McGuire PK, Frith CD. Disordered functional connectivity in schizophrenia. Psychol Med 1996;26:663-667. [PubMed: 8817700][editorial] 
8. Friston KJ, Frith CD. Schizophrenia: a disconnection syndrome? Clin Neurosci 1995;3:89-97. [PubMed: 7583624]

9. Harrison PJ. The neuropathology of schizophrenia: a critical review of the data and their interpretation. Brain 1999;122(Pt 4):593-624. [PubMed: 10219775]

10. Cotter DR, Pariante CM, Everall IP. Glial cell abnormalities in major psychiatric disorders: the evidence and implications. Brain Res Bull 2001;55:585-595. [PubMed: 11576755]

11. Uranova N, Orlovskaya D, Vikhreva O, et al. Electron microscopy of oligodendroglia in severe mental illness. Brain Res Bull 2001;55:597-610. [PubMed: 11576756]

12. Hakak Y, Walker JR, Li C, et al. Genome-wide expression analysis reveals dysregulation of myelination-related genes in chronic schizophrenia. Proc Natl Acad Sci U S A 2001;98:4746-4751. [PubMed: 11296301]

13. Lim KO, Helpern JA. Neuropsychiatric applications of DTI: a review. NMR Biomed 2002;15:587593. [PubMed: 12489105]

$14 \bullet$ • Kubicki M, Westin CF, Nestor PG, et al. Cingulate fasciculus integrity disruption in schizophrenia: a magnetic resonance diffusion tensor imaging study. Biol Psychiatry 2003;54:1171-1180. [PubMed: 14643084]•• of outstanding interestThis study is the first DTI study of schizophrenia to investigate the cingulum bundle, the main fiber tract in the limbic system. The cingulate bundle showed reduced anisotropy, bilaterally, in schizophrenia patients compared with controls.

15. Mottershead JP, Schmierer K, Clemence M, et al. High field MRI correlates of myelin content and axonal density in multiple sclerosis: a post-mortem study of the spinal cord. J Neurol 2003;250:12931301. [PubMed: 14648144]

16. Foong J, Symms MR, Barker GJ, et al. Neuropathological abnormalities in schizophrenia: evidence from magnetization transfer imaging. Brain 2001;124(Pt 5):882-892. [PubMed: 11335691]

17. Bagary MS, Symms MR, Barker GJ, et al. Gray and white matter brain abnormalities in first-episode schizophrenia inferred from magnetization transfer imaging. Arch Gen Psychiatry 2003;60:779-788. [PubMed: 12912761]

18. Ashburner J, Friston KJ. Voxel-based morphometry: the methods. Neuroimage 2000;11(6 Pt 1):805821. [PubMed: 10860804]

19. Sigmundsson T, Suckling J, Maier M, et al. Structural abnormalities in frontal, temporal, and limbic regions and interconnecting white matter tracts in schizophrenic patients with prominent negative symptoms. Am J Psychiatry 2001;158:234-243. [PubMed: 11156806]

20. Paillere-Martinot M, Caclin A, Artiges E, et al. Cerebral gray and white matter reductions and clinical correlates in patients with early onset schizophrenia. Schizophr Res 2001;50:19-26. [PubMed: 11378311]

21. Suddath RL, Christison GW, Torrey EF, et al. Anatomical abnormalities in the brains of monozygotic twins discordant for schizophrenia. N Engl J Med 1990;322:789-794. [PubMed: 2308615]

22. Wible CG, Shenton ME, Hokama H, et al. Prefrontal cortex and schizophrenia: a quantitative magnetic resonance imaging study. Arch Gen Psychiatry 1995;52:279-288. [PubMed: 7702444]

23. Breier A, Buchanan RW, Elkashef E, et al. Brain morphology and schizophrenia: a magnetic resonance imaging study of limbic, prefrontal cortex, and caudate structures. Arch Gen Psychiatry 1992;49:921-926. [PubMed: 1449382]

24. Hulshoff Pol HE, Brans RG, van Haren NE, et al. Gray and white matter volume abnormalities in monozygotic and same-gender dizygotic twins discordant for schizophrenia. Biol Psychiatry 2004;55:126-130. [PubMed: 14732591]

$25 \bullet \bullet$. Christensen J, Holcomb J, Garver DL. State-related changes in cerebral white matter may underlie psychosis exacerbation. Psychiatry Res 2004;130:71-78. [PubMed: 14972369]•• of outstanding interestThis interesting study of whole white matter volume showed white matter volume reduction in schizophrenia following a short regimen of medication treatment.

26. Spalletta G, Tomaiuolo F, Marino V, et al. Chronic schizophrenia as a brain misconnection syndrome: a white matter voxel-based morphometry study. Schizophr Res 2003;64:15-23. [PubMed: 14511797]

$27 \bullet$. Hulshoff Pol HE, Schnack HG, Mandl RC, et al. Focal white matter density changes in schizophrenia: reduced inter-hemispheric connectivity. Neuroimage 2004;21:27-35. [PubMed: 14741639]•• of outstanding interestThis study of focal white matter density changes in 
schizophrenia used VBM methods and reported decreased white matter density in the corpus callosum in schizophrenia.

28. Zhou SY, Suzuki M, Hagino H, et al. Decreased volume and increased asymmetry of the anterior limb of the internal capsule in patients with schizophrenia. Biol Psychiatry 2003;54:427-436. [PubMed: 12915287]

29. Mitelman SA, Shihabuddin L, Brickman AM, et al. MRI assessment of gray and white matter distribution in Brodmann's areas of the cortex in patients with schizophrenia with good and poor outcomes. Am J Psychiatry 2003;160:2154-2168. [PubMed: 14638586]

$30 \bullet$. Bartzokis G, Nuechterlein KH, Lu PH, et al. Dysregulated brain development in adult men with schizophrenia: a magnetic resonance imaging study. Biol Psychiatry 2003;53:412-421. [PubMed: 12614994] of special interestThis study evaluated white matter volume, segmented into separate lobes, in which a relationship between gray and white matter volumes and age was found in controls, but not in patients with schizophrenia. This finding suggests that age-related changes may be different in controls compared with neuropathological populations such as patients with schizophrenia.

31. Mathalon DH, Pfefferbaum A, Lim KO, et al. Compounded brain volume deficits in schizophreniaalcoholism comorbidity. Arch Gen Psychiatry 2003;60:245-252. [PubMed: 12622657]

32. Ho BC, Alicata D, Ward J, et al. Untreated initial psychosis: relation to cognitive deficits and brain morphology in first-episode schizophrenia. Am J Psychiatry 2003;160:142-148. [PubMed: 12505813]

$33 \cdot$. Ho BC, Andreasen NC, Nopoulos P, et al. Progressive structural brain abnormalities and their relationship to clinical outcome: a longitudinal magnetic resonance imaging study early in schizophrenia. Arch Gen Psychiatry 2003;60:585-594. [PubMed: 12796222]• of special interestDespite age differences between patients with schizophrenia and controls, this is an interesting study that documents a decrease in prefrontal white matter volume in schizophrenia, which was correlated with negative symptom severity.

34. Milev P, Ho BC, Arndt S, et al. Initial magnetic resonance imaging volumetric brain measurements and outcome in schizophrenia: a prospective longitudinal study with 5-year follow-up. Biol Psychiatry 2003;54:608-615. [PubMed: 13129655]

35. Arango C, Breier A, McMahon R, et al. The relationship of clozapine and haloperidol treatment response to prefrontal, hippocampal, and caudate brain volumes. Am J Psychiatry 2003;160:14211427. [PubMed: 12900303]

36. Highley JR, DeLisi LE, Roberts N, et al. Sex-dependent effects of schizophrenia: an MRI study of gyral folding, and cortical and white matter volume. Psychiatry Res 2003;124:11-23. [PubMed: 14511792]

37. Hyde TM, Ziegler JC, Weinberger DR. Psychiatric disturbances in metachromatic leukodystrophy: insights into the neurobiology of psychosis. Arch Neurol 1992;49:401-406. [PubMed: 1532712]

38. Benes FM, Turtle M, Khan Y, et al. Myelination of a key relay zone in the hippocampal formation occurs in the human brain during childhood, adolescence, and adulthood. Arch Gen Psychiatry 1994;51:477-484. [PubMed: 8192550]

39. Basser PJ, Mattiello J, LeBihan D. MR diffusion tensor spectroscopy and imaging. Biophys J 1994;66:259-267. [PubMed: 8130344]

40. Foong J, Symms MR, Barker GJ, et al. Investigating regional white matter in schizophrenia using diffusion tensor imaging. Neuroreport 2002;13:333-336. [PubMed: 11930133]

41. Agartz I, Andersson JL, Skare S. Abnormal brain white matter in schizophrenia: a diffusion tensor imaging study. Neuroreport 2001;12:2251-2254. [PubMed: 11447344]

42. Kubicki M, Westin CF, Maier SE, et al. Uncinate fasciculus findings in schizophrenia: a magnetic resonance diffusion tensor imaging study. Am J Psychiatry 2002;159:813-820. [PubMed: 11986136]

43. Buchsbaum MS, Tang CY, Peled S, et al. MRI white matter diffusion anisotropy and PET metabolic rate in schizophrenia. Neuroreport 1998;9:425-430. [PubMed: 9512384]

44. Lim KO, Hedehus M, Moseley M, et al. Compromised white matter tract integrity in schizophrenia inferred from diffusion tensor imaging. Arch Gen Psychiatry 1999;56:367-374. [PubMed: 10197834] 
45. Wang F, Sun Z, Du X, et al. A diffusion tensor imaging study of middle and superior cerebellar peduncle in male patients with schizophrenia. Neurosci Lett 2003;348:135-138. [PubMed: 12932812]

46. Sun Z, Wang F, Cui L, et al. Abnormal anterior cingulum in patients with schizophrenia: a diffusion tensor imaging study. Neuroreport 2003;14:1833-1836. [PubMed: 14534430]

47 •. Burns J, Job D, Bastin ME, et al. Structural disconnectivity in schizophrenia: a diffusion tensor magnetic resonance imaging study. Br J Psychiatry 2003;182:439-443. [PubMed: 12724248]• of special interestThis VBM study of diffusion data investigated fronto-temporal connections in schizophrenia and reported reduced anisotropy in the arcuate and uncinate fasciculi.

48. Kumra S, Ashtari M, McMeniman M, et al. Reduced frontal white matter integrity in early-onset schizophrenia: a preliminary study. Biol Psychiatry 2004;55:1138-1145. [PubMed: 15184032]

49. Wolkin A, Choi SJ, Szilagyi S, et al. Inferior frontal white matter anisotropy and negative symptoms of schizophrenia: a diffusion tensor imaging study. Am J Psychiatry 2003;160:572-574. [PubMed: 12611842]

50. Ardekani BA, Nierenberg J, Hoptman MJ, et al. MRI study of white matter diffusion anisotropy in schizophrenia. Neuroreport 2003;14:2025-2029. [PubMed: 14600491]

$51 \bullet$. Hubl D, Koenig T, Strik W, et al. Pathways that make voices: white matter changes in auditory hallucinations. Arch Gen Psychiatry 2004;61:658-668. [PubMed: 15237078]•• of outstanding interestThis interesting study describes the relationship between increased fractional anisotropy in patients diagnosed with schizophrenia who evince auditory hallucinations, compared with patients diagnosed with schizophrenia without auditory hallucinations.

$52 \bullet$. Park HJ, Kubicki M, Shenton ME, et al. Spatial normalization of diffusion tensor MRI using multiple channels. Neuroimage 2003;20:1995-2009. [PubMed: 14683705]•• of outstanding interestThis VBM study is important because, unlike other such studies, it used a precise registration method that takes into account both tensor and structural data. Using this approach, the investigators reported decreased white matter asymmetries in schizophrenia patients compared with controls.

53 •. Minami T, Nobuhara K, Okugawa G, et al. Diffusion tensor magnetic resonance imaging of disruption of regional white matter in schizophrenia. Neuropsychobiology 2003;47:141-145. [PubMed: 12759557]• of special interestDespite the small number of participants, this is an interesting study that shows the relationship between fractional anisotropy and medication, where fractional anisotropy of left frontal white matter was correlated significantly with dosage of antipsychotic medication.

54. Kubicki M, Westin CF, Nestor PG, et al. Cingulate fasciculus integrity disruption in schizophrenia: a magnetic resonance diffusion tensor imaging study. Biol Psychiatry 2003;54:1171-1180. [PubMed: 14643084]

55. Okugawa G, Nobuhara K, Minami T, et al. Subtle disruption of the middle cerebellar peduncles in patients with schizophrenia. Neuropsychobiology 2004;50:119-123. [PubMed: 15292664]

56. Foong J, Maier M, Barker GJ, et al. In vivo investigation of white matter pathology in schizophrenia with magnetisation transfer imaging. J Neurol Neurosurg Psychiatry 2000;68:70-74. [PubMed: 10601405]

$57 \bullet \bullet$. Flynn SW, Lang DJ, Mackay AL, et al. Abnormalities of myelination in schizophrenia detected in vivo with MRI, and post-mortem with analysis of oligodendrocyte proteins. Mol Psychiatry 2003;8:811-820. [PubMed: 12931208]•• of outstanding interestThis study combined a neuroimaging technique sensitive to myelin density with a postmortem investigation of oligodendrocyte proteins in schizophrenia, and reported decreased immunoreactivity in two myelinassociated proteins in schizophrenia.

58. Highley JR, Esiri MM, McDonald B, et al. The size and fiber composition of the anterior commissure with respect to gender and schizophrenia. Biol Psychiatry 1999;45:1120-1127. [PubMed: 10331103]

59. Highley JR, Esiri MM, McDonald B, et al. The size and fibre composition of the corpus callosum with respect to gender and schizophrenia: a post-mortem study. Brain 1999;122(Pt 1):99-110. [PubMed: 10050898]

60. Highley JR, Walker MA, Esiri MM, et al. Asymmetry of the uncinate fasciculus: a post-mortem study of normal subjects and patients with schizophrenia. Cereb Cortex 2002;12:1218-1224. [PubMed: 12379610] 
61. Davis KL, Stewart DG, Friedman JI, et al. White matter changes in schizophrenia: evidence for myelin-related dysfunction. Arch Gen Psychiatry 2003;60:443-456. [PubMed: 12742865]

$62 \bullet$. Eastwood SL, Harrison PJ. Interstitial white matter neurons express less reelin and are abnormally distributed in schizophrenia: towards an integration of molecular and morphologic aspects of the neurodevelopmental hypothesis. Mol Psychiatry 2003;8:821-831.•• of outstanding interestThis study showed increased density of interstitial neurons and decreased expression of reelin in superficial temporal white matter in schizophrenia.

63. Kirkpatrick B, Messias NC, Conley RC, et al. Interstitial cells of the white matter in the dorsolateral prefrontal cortex in deficit and nondeficit schizophrenia. J Nerv Ment Dis 2003;191:563-567. [PubMed: 14504564]

64. Rioux L, Nissanov J, Lauber K, et al. Distribution of microtubule-associated protein MAP2immunoreactive interstitial neurons in the parahippocampal white matter in subjects with schizophrenia. Am J Psychiatry 2003;160:149-155. [PubMed: 12505814]

65. Uranova NA, Vostrikov VM, Orlovskaya DD, et al. Oligodendroglial density in the prefrontal cortex in schizophrenia and mood disorders: a study from the Stanley Neuropathology Consortium. Schizophr Res 2004;67:269-275. [PubMed: 14984887]

$66 \cdot$ Hof PR, Haroutunian V, Friedrich VL Jr, et al. Loss and altered spatial distribution of oligodendrocytes in the superior frontal gyrus in schizophrenia. Biol Psychiatry 2003;53:10751085. [PubMed: 12814859]• of special interestDespite the small number of specimens tested, this study showed oligodendrocyte alterations in white matter in schizophrenia.

67 •. Tkachev D, Mimmack ML, Ryan MM, et al. Oligodendrocyte dysfunction in schizophrenia and bipolar disorder. Lancet 2003;362:798-805. [PubMed: 13678875]• of special interestThis study showed a reduction in the expression of genes related to oligodendrocyte and myelination process in schizophrenia.

68. Aston C, Jiang L, Sokolov BP. Microarray analysis of postmortem temporal cortex from patients with schizophrenia. J Neurosci Res 2004;77:858-866. [PubMed: 15334603]

$69 \bullet \bullet$. Marner L, Pakkenberg B. Total length of nerve fibers in prefrontal and global white matter of chronic schizophrenics. J Psychiatr Res 2003;37:539-547. [PubMed: 14563386]•• of outstanding interestThis interesting study calculated the total length of white matter fibers in schizophrenia.

70. Akbarian S, Kim JJ, Potkin SG, et al. Maldistribution of interstitial neurons in prefrontal white matter of the brains of schizophrenic patients. Arch Gen Psychiatry 1996;53:425-436. [PubMed: 8624186]

71. Akbarian S, Vinuela A, Kim JJ, et al. Distorted distribution of nicotinamideadenine dinucleotide phosphate-diaphorase neurons in temporal lobe of patients with schizophrenia implies anomalous cortical development. Arch Gen Psychiatry 1993;50:178-187. [PubMed: 7679892]

72. Kirkpatrick B, Conley RC, Kakoyannis A, et al. Interstitial cells of the white matter in the inferior parietal cortex in schizophrenia: an unbiased cell-counting study. Synapse 1999;34:95-102. [PubMed: 10502308] 

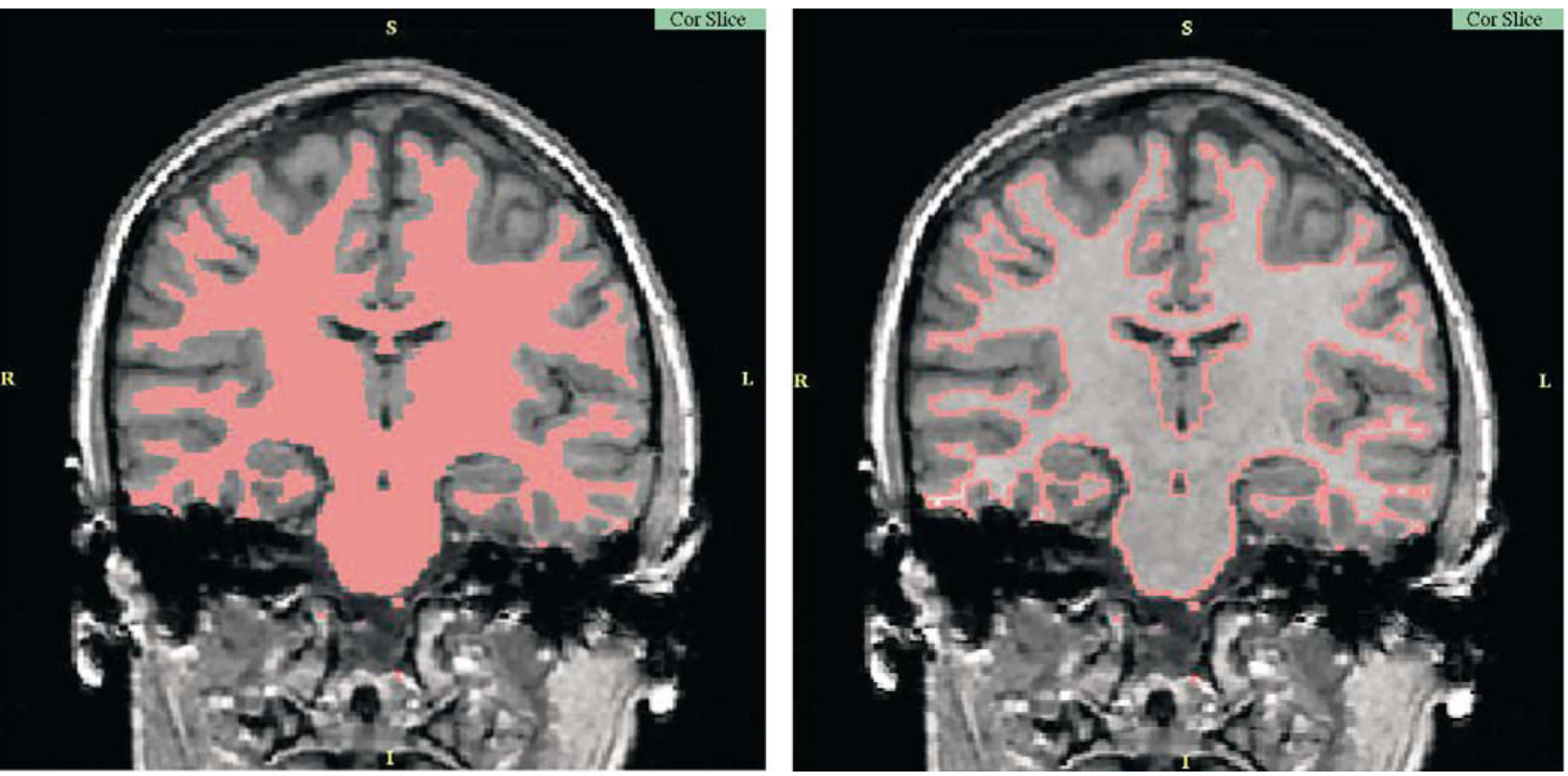

Figure 1. Automatic segmentation of white matter

Magnetic resonance imaging structural data acquired on a 1.5 T magnet (courtesy of Sylvain Bouix). 

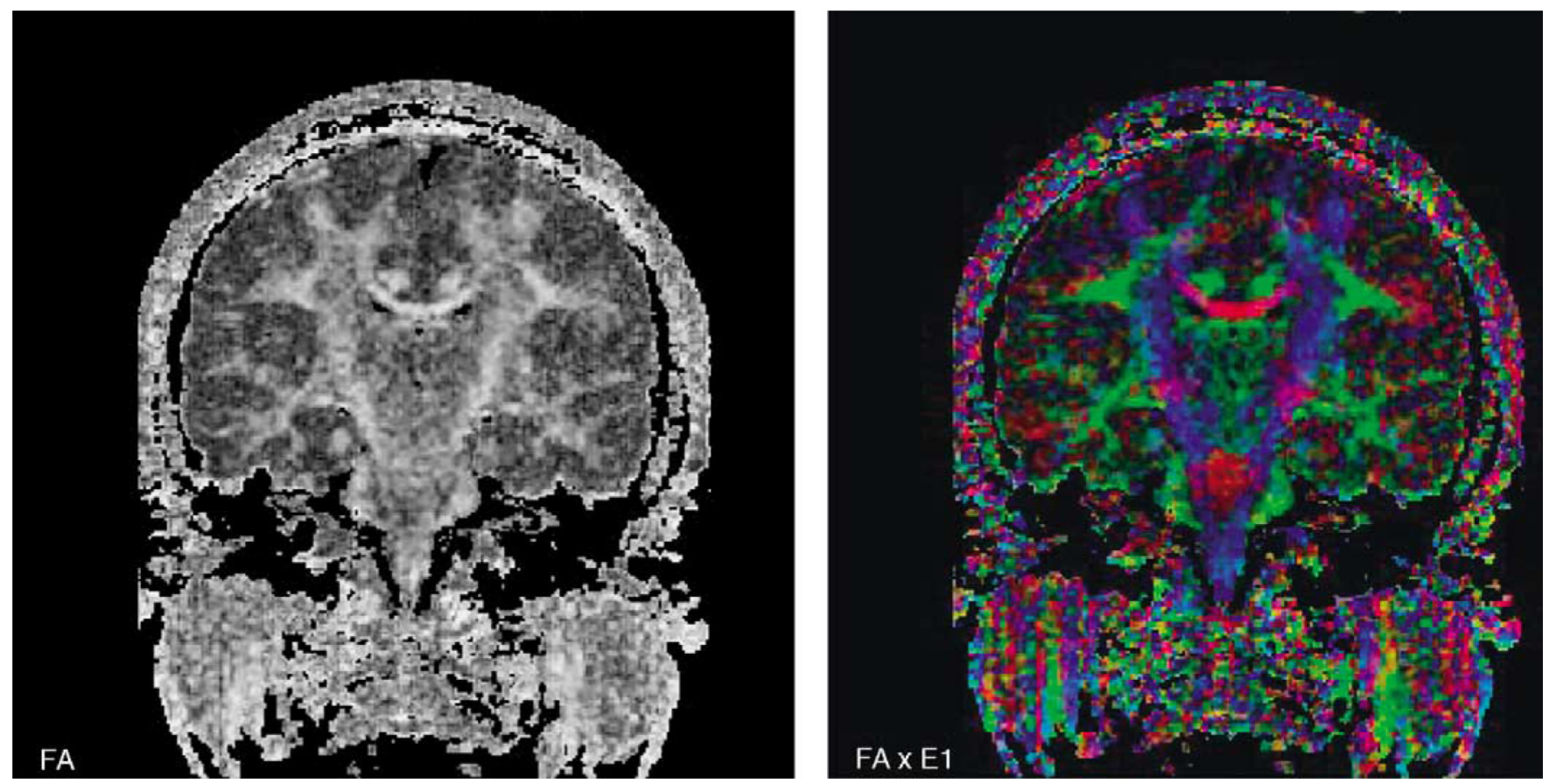

Figure 2. Diffusion tensor images acquired on 1.5 $\mathrm{T}$ magnetic resonance magnet

On the left is a fractional anisotropy map, and on the right is a tensor map with the colors corresponding to fiber orientation (i.e. blue $=$ superior to inferior, red $=$ left to right, and green $=$ posterior to anterior). 

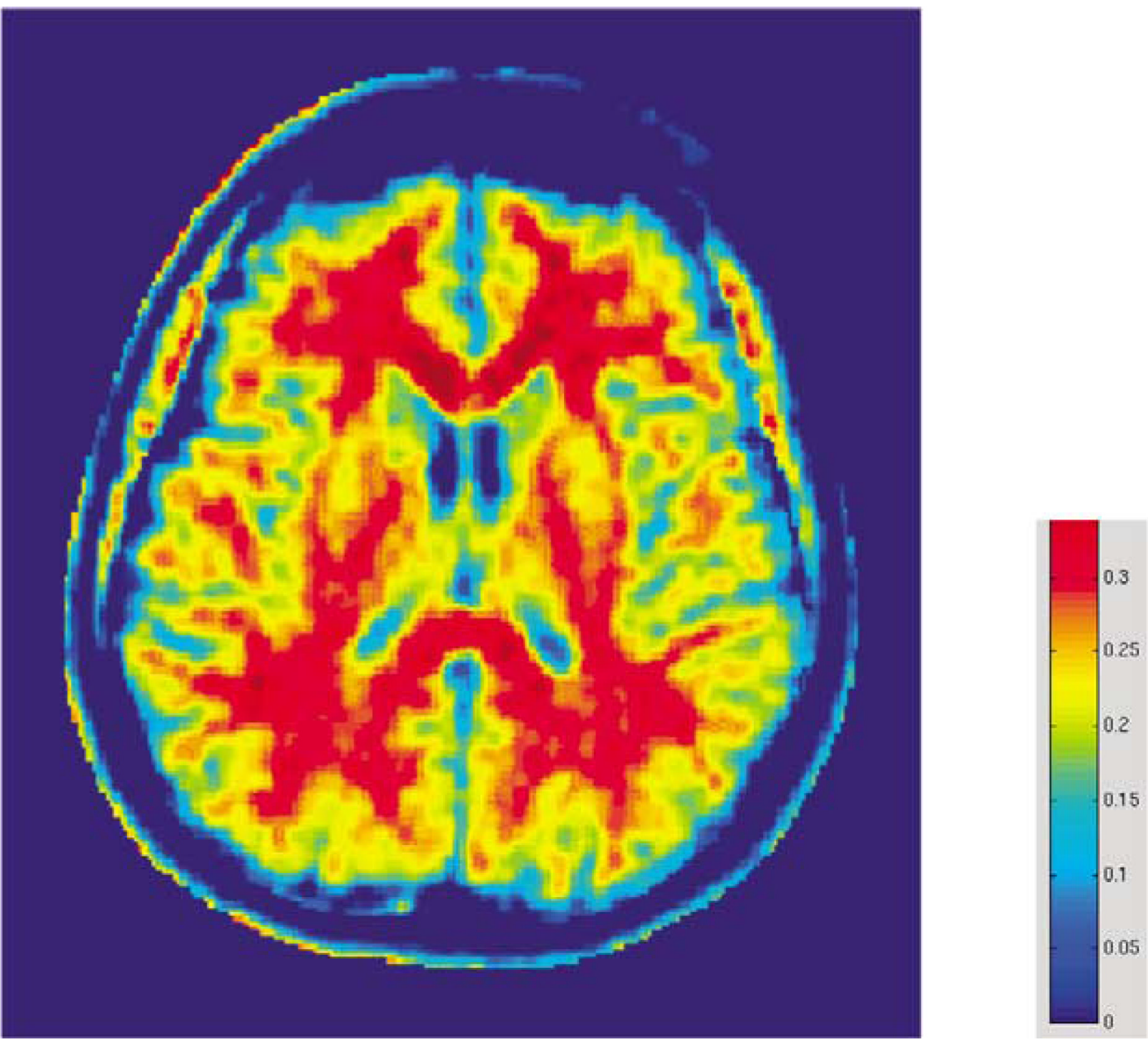

Figure 3. Map of magnetization transfer ratio showing distribution of myelin in the brain The red color indicates higher myelin density in the white matter (note the highest myelin density is in the corpus callosum), while the yellow color indicates lower myelin density in the gray matter. 


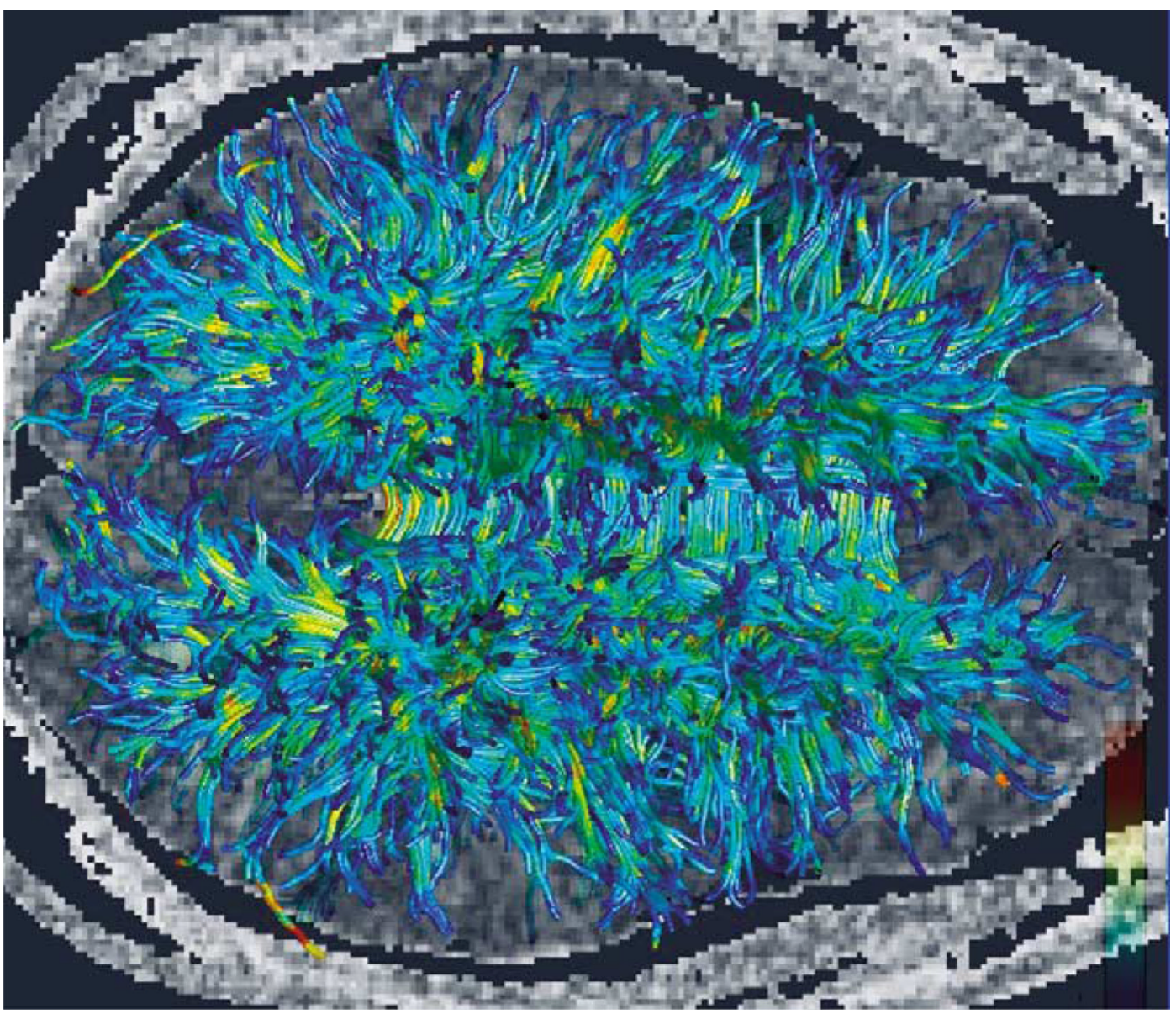

Figure 4. Fiber tractography

Based on diffusion data acquired on a $3 \mathrm{~T}$ magnet demonstrating major long fiber tracts of the brain (courtesy of Hae-Jeong Park PhD, currently at Laboratory of Molecular Neuroimaging, Department of Diagnostic Radiology, Yonsei University College of Medicine, Seoul, South Korea). 


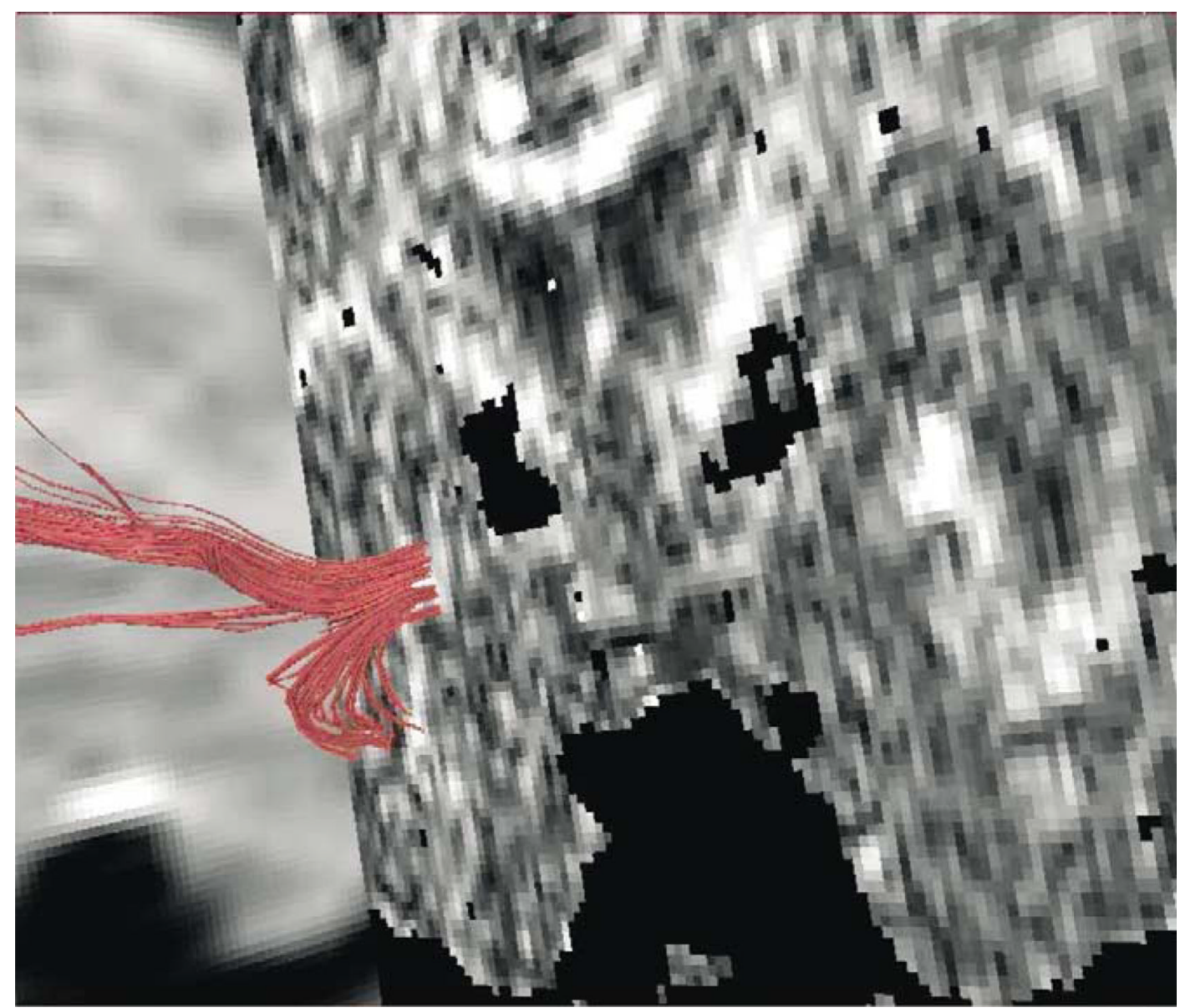

Figure 5. Fiber tractography of the uncinate fasciculus

Fiber tractography of the uncinate fasciculus is co-registered with a fractional anisotropy coronal image, and shows the relationship of this fiber bundle to surrounding structures. 
Table 1

Structural magnetic resonance imaging (MRI) white matter findings in schizophrenia

\begin{tabular}{|c|c|c|c|c|}
\hline Author & Method & Study participants & MR parameters & Findings \\
\hline Hulshoff Pol et al. (2004) [24] & $\begin{array}{l}\text { Total white matter } \\
\text { volume measured }\end{array}$ & $\begin{array}{l}11 \mathrm{MZ} \text { twins discordant for } \\
\text { schizophrenia }(6 \mathrm{M} / 5 \mathrm{~F} \text {, mean } \\
\text { age } 39), 11 \mathrm{DZ} \text { twins } \\
\text { discordant for schizophrenia } \\
(5 \mathrm{M} / 6 \mathrm{~F} \text {, mean age } 34.5), 11 \\
\mathrm{MZ} \text { healthy twins }(6 \mathrm{M} / 5 \mathrm{~F} \text {, } \\
\text { mean age } 37.4) \text {, and } 11 \mathrm{DZ} \\
\text { healthy twins }(5 \mathrm{M} / 6 \mathrm{~F} \text {, mean } \\
\text { age } 32.5)\end{array}$ & $\begin{array}{l}1.5 \mathrm{~T} \text { scanner, } 1.2 \mathrm{~mm} \\
\text { coronal } \mathrm{T} 1,1.6 \mathrm{~mm} \text { coronal } \\
\mathrm{T} 2\end{array}$ & $\begin{array}{l}\text { Decreased white matter } \\
\text { lvolume in discordant } \\
\text { twins }\end{array}$ \\
\hline
\end{tabular}

Christensen et al. (2004) [25**]

Spalletta et al. (2003) [26]

Hulshoff Pol et al. (2004) [27*]

Zhou et al. (2003) [28]

Mitelman et al. (2003) [29]

Bartzokis et al. (2003) [30]

Mathalon et al. (2003) [31]

Ho et al. (2003) [32]

Ho et al. (2003) [33]

Milev et al. (2003) [34]

Arango et al. (2003) [35]
Total cerebral white $\quad 16$ recently decompensated $\quad 1.5 \mathrm{~T}$ scanner, $2 \mathrm{~mm} \quad$ Patients who responded to matter volume assessed atSZs (11M/5F, mean age 32.1)sagittal MPRAGE, $2 \mathrm{~mm}$ medication showed a 4-week intervals at the baseline, and after 4 T2/PD decrease in the white weeks treatment, 8 controls $(6 \mathrm{M} / 2 \mathrm{~F}$, mean age 29.2$)$

scanned in similar intervals

VBM of white matter 28 chronic SZs $(14 \mathrm{M} / 14 \mathrm{~F}, \quad 1.5 \mathrm{~T}$ scanner, $1 \mathrm{~mm}$ mean age 34.6), 28 controls MPRAGE $(14 \mathrm{M} / 14 \mathrm{~F}$, mean age 34.4$)$ matter volume compared with other groups

Decrease in white matter density bilaterally in postcentral gyrus, inferior frontal gyrus, medial and lateral orbital gyri, gyrus rectus, and unilaterally (left) in superior temporal gyrus

VBM of white matter

$159 \mathrm{SZs}(112 \mathrm{M} / 47 \mathrm{~F}$, mean $1.5 \mathrm{~T}$ scanner, $1.2 \mathrm{~mm}$ Decrease in white matter age 35.6), 158 controls coronal $\mathrm{T} 1,1.6 \mathrm{~mm}$ coronaldensity in genu and (106M/52F, mean age 37.7$)$ T2 truncus of the corpus callosum, right anterior internal capsule and anterior commisure

VBM of white matter $53 \mathrm{SZs}(27 \mathrm{M} / 26 \mathrm{~F}$, mean age $1.5 \mathrm{~T}$ scanner, $1 \mathrm{~mm}$ (verified with ROI)

$26.5), 48$ controls $(26 \mathrm{M} / 22 \mathrm{~F}$, coronal FLASH Decreased volumes of the anterior limb of the internal capsule, bilaterally, and increased right $>$ left asymmetry

Automatic segmentation $37 \mathrm{SZs}(27 \mathrm{M} / 10 \mathrm{~F}), 13$ with $1.5 \mathrm{~T}$ scanner, $1.2 \mathrm{~mm}$ T1 Smaller volumes for poor into frontal, temporal andpoor outcome (mean age occipital regions 47.1), 24 with good outcome (mean age 41), 37 controls outcome patients in temporal and occipital regions $(23 \mathrm{M} / 14 \mathrm{~F})$

Gray and white matter of 35 male SZs (mean age 27.5),1.5 T scanner, $3 \mathrm{~mm}$ dual Interactions of diagnosis, frontal and temporal 52 male controls (mean age spin echo, $3 \mathrm{~mm}$ inversion age and gray to white lobes were assessed using30.5) recovery sequence matter ratios. In controls, semiautomatic matter ratios. In controls, gray to white matter ratio declined with age while in SZs it did not

Semiautomated $\quad 35$ male SZs comorbid for $1.5 \mathrm{~T}$ scanner, $5 \mathrm{~mm}$ thick White matter volume segmentation white and alcoholism (mean age 38.5), axial dual echo slices (withreduction (nonsignificant) gray matter, plus six 64 male SZs (mean age 40), $622.5 \mathrm{~mm}$ interslice gap) in prefrontal white matter geometrically defined brain regions male alcoholics (mean age 44.6 ), and 62 male controls, (mean age 42.3) in comorbid patients compared with controls

Total white matter volumes as well as volumes of frontal, temporal, parietal and 156 subjects $(97 \mathrm{M} / 59 \mathrm{~F})$ were $1.5 \mathrm{~T}$ scanner, $1.5 \mathrm{~mm} \quad$ No correlations were evaluated during their first coronal SPGRs, $3 \mathrm{~mm}$ axialnoted between duration of episode of psychosis double echo untreated psychosis and were evaluated.

Image normalization to $73 \mathrm{SZs}(53 \mathrm{M} / 20 \mathrm{~F}$, mean age $1.5 \mathrm{~T}$ scanner, $1.5 \mathrm{~mm} \quad$ Progressive reduction of the Talairach space 24.5), 23 controls $(15 \mathrm{M} / 8 \mathrm{~F}$, coronal SPGRs, $3 \mathrm{~mm}$ axialfrontal lobe white matter $\begin{array}{ll}\begin{array}{l}\text { followed by automated mean age 26.9) } \\ \text { segmentation into frontal, }\end{array} & \text { in patients, associated } \\ \text { with greater negative }\end{array}$ segmentation into frontal, temporal and parietal white matter. Scanned twice at 3-year intervals White matter volumes of $123 \mathrm{SZs}(89 \mathrm{M} / 34 \mathrm{~F})$ frontal and temporal lobes were evaluated following automated segmentation procedure

Prefrontal white matt obtained after symptom severity. Age differences between SZs and controls 1.5 T scanner, $1.5 \mathrm{~mm} \quad$ None of the white matter coronal SPGRs, $3 \mathrm{~mm}$ dualmeasures were predictive echo coronals of the outcome after 5 years of disease

$22 \mathrm{SZs}(14 \mathrm{M} / 8 \mathrm{~F})$ treated with2 $\mathrm{T}$ scanner, $3 \mathrm{~mm}$ coronal No relationship between clonazepine (mean age 35.5), T1 sequence treatment and white 


\begin{tabular}{|c|c|c|c|}
\hline Author & Method & Study participants & Findings \\
\hline & $\begin{array}{l}\text { thresholding on image } \\
\text { intensity was assessed at } \\
10 \text {-week intervals before } \\
\text { and after medication } \\
\text { treatment }\end{array}$ & $\begin{array}{l}\text { and } 23 \mathrm{SZs}(16 \mathrm{M} / 7 \mathrm{~F}) \text { treated } \\
\text { t with haloperidol (mean age } \\
34.5)\end{array}$ & $\begin{array}{l}\text { matter volumes was } \\
\text { observed }\end{array}$ \\
\hline Highley et al. (2003) [36] & $\begin{array}{l}\text { White matter divided } \\
\text { into: frontal, temporal and } \\
\text { parieto-occipital regions }\end{array}$ & $\begin{array}{l}61 \text { chronic SZs }(40 \mathrm{M} \text {, mean } 1.5 \mathrm{~T} \text { scanner, } 1.5 \mathrm{~mm} \\
\text { dage } 30.9 ; 21 \mathrm{~F} \text {, mean age } 33.4) \text {, coronal SPGR } \\
42 \text { controls }(21 \mathrm{M} \text {, mean age } \\
30.5 ; 21 \mathrm{~F} \text {, mean age } 40.3)\end{array}$ & $\begin{array}{l}\text { Parieto-occipital white } \\
\text { matter volume decreased } \\
\text { in females, but increased } \\
\text { in males SZs compared } \\
\text { with controls (significant } \\
\text { differences in age) }\end{array}$ \\
\hline
\end{tabular}

MR, magnetic resonance; MZ, monozygotic; DZ, dizygotic; SZ, schizophrenia patient; VBM, voxel-based morphometry; ROI, region of interest; SPGR, spolied gradient-recalled echo. 
Table 2

Diffusion tensor imaging white matter findings in schizophrenia

\begin{tabular}{|c|c|c|c|c|}
\hline Author & Method & Study participants & MR parameters & Findings \\
\hline $\begin{array}{l}\text { Wang et al. (2003) } \\
\text { [45] }\end{array}$ & $\begin{array}{l}\text { FA and mean } \\
\text { diffusivity of } \\
\text { WM measured } \\
\text { in the superior } \\
\text { and middle } \\
\text { cerebellar } \\
\text { peduncles }\end{array}$ & \multicolumn{3}{|c|}{$\begin{array}{l}29 \text { male SZs (mean age } 1.5 \mathrm{~T} \mathrm{MR} \text { scanner, axial, } 25 \text { directions, matrix }=128 \times \text { No differences observed between } \\
\text { 28.45), and } 20 \text { male } 128, \mathrm{FOV}=24 \times 24 \mathrm{~cm}^{2} \text {, slice thickness/interval }=5.0 / 1.0 \text { groups, although the authors note } \\
\text { that the methodology may not have } \\
\text { controls (mean age 26). } \mathrm{mm}\end{array} \begin{array}{l}\begin{array}{l}\text { been sufficiently sensitive to discern } \\
\text { differences }\end{array} \\
\begin{array}{l}\text { All right-handed } \\
\end{array}\end{array}$} \\
\hline $\begin{array}{l}\text { Sun et al. (2003) } \\
\text { [46] }\end{array}$ & $\begin{array}{l}\text { FA was } \\
\text { measured in } \\
\text { multiple brain } \\
\text { regions } \\
\text { including WM } \\
\text { in temporal } \\
\text { lobe, frontal } \\
\text { lobe, occipital } \\
\text { lobe, genu and } \\
\text { splenium of } \\
\text { CC, internal } \\
\text { capsule, } \\
\text { anterior } \\
\text { cingulate, and } \\
\text { optic radiation }\end{array}$ & $\begin{array}{l}30 \mathrm{SZs}(18 \mathrm{M} / 12 \mathrm{~F}, \text { mear } \\
\text { age } 27.4), \text { and } 19 \\
\text { controls }(12 \mathrm{M} / 7 \mathrm{~F} \text {, mear } \\
\text { age } 25.7) \text {. All right- } \\
\text { handed }\end{array}$ & $\begin{array}{l}\text { n1.5 T MR scanner, axial, } 25 \text { directions, matrix }=128 \times \\
128, \mathrm{FOV}=24 \times 24 \mathrm{~cm}^{2}, \mathrm{NEX}=1 \text {, slice thickness } / \\
\text { ninterval }=5.0 / 1.5 \mathrm{~mm}\end{array}$ & $\begin{array}{l}\text { FA values were decreased in the } \\
\text { anterior cingulum, supporting the } \\
\text { notion that abnormal WM integrity is } \\
\text { evident in SZs. The authors note that } \\
\text { this finding needs to be confirmed in } \\
\text { additional studies }\end{array}$ \\
\hline $\begin{array}{l}\text { Park et al. (2003) } \\
{\left[52^{* *}\right]}\end{array}$ & $\begin{array}{l}\text { Voxel-based } \\
\text { analysis of FA } \\
\text { hemisphere } \\
\text { asymmetry }\end{array}$ & \multicolumn{3}{|c|}{ 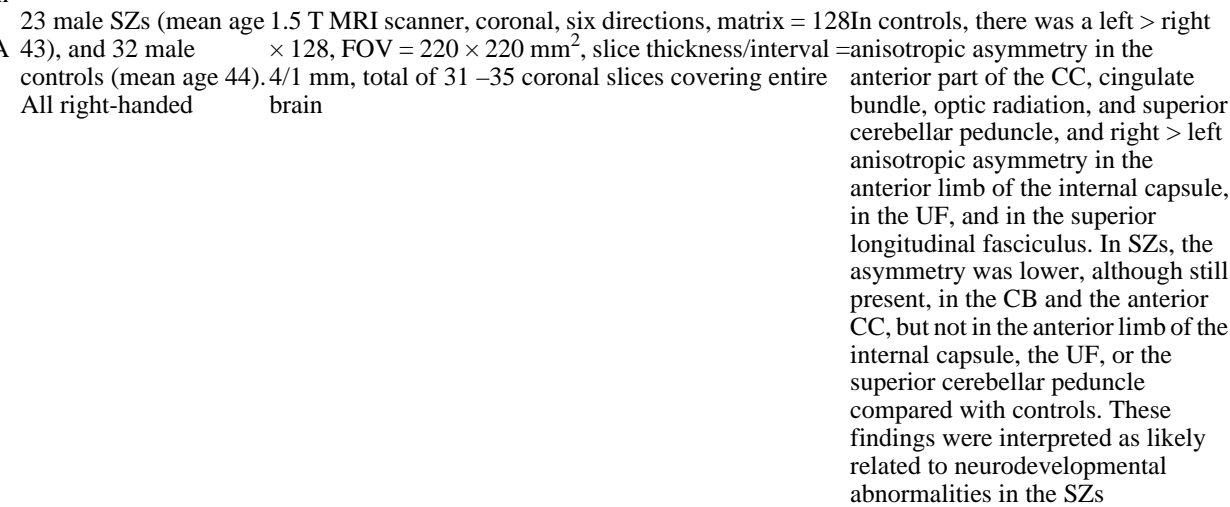 } \\
\hline $\begin{array}{l}\text { Ardekani et al. } \\
(2003)[50]\end{array}$ & $\begin{array}{l}\text { Voxel-wise } \\
\text { methods were } \\
\text { used to evaluate } \\
\text { FA }\end{array}$ & $\begin{array}{l}14 \mathrm{SZs}(11 \mathrm{M} / 3 \mathrm{~F}, 7 \mathrm{SZ} \\
\text { and } 7 \mathrm{SZAFF}, \text { mean age } \\
\text { e30.8), and } 14 \text { controls } \\
(11 \mathrm{M} / 3 \mathrm{~F}, \text { mean age } \\
33.5)\end{array}$ & $\begin{array}{l}1.5 \mathrm{~T} \text { MR scanner, axial, six directions, matrix }=128 \times \\
\mathrm{e} 128, \mathrm{FOV}=240 \mathrm{~cm}^{2}, \mathrm{NEX}=4 \text {, slice thickness/interval } \\
=5 / 0 \mathrm{~mm}, 20 \text { slices }\end{array}$ & $\begin{array}{l}\text { Reduced FA in SZs compared with } \\
\text { bilaterally, frontal region just dorsal } \\
\text { and lateral to the genu of the CC in } \\
\text { the region of the cingulate gyrus } \\
\text { bilaterally, the body of the CC, deep } \\
\text { occipital WM, splenium, left STG, } \\
\text { and PHG bilaterally }\end{array}$ \\
\hline $\begin{array}{l}\text { Minami et al. }(2003) \\
{\left[53^{\circ}\right]}\end{array}$ & $\begin{array}{l}\text { FA used to } \\
\text { evaluate WM in } \\
\text { frontal, } \\
\text { temporal, } \\
\text { parietal, and } \\
\text { occipital lobe in } \\
\text { SZs and in } \\
\text { controls }\end{array}$ & $\begin{array}{l}12 \mathrm{SZs}(5 \mathrm{M} / 7 \mathrm{~F} \text {, mean } \\
\text { nage } 30.8) \text { and } 11 \\
\text { controls }(7 \mathrm{M} / 4 \mathrm{~F}, \text { mean } \\
\text { age } 29.0) \\
\text { n }\end{array}$ & $\begin{array}{l}1.5 \mathrm{~T} \text { MR scanner, axial, six directions, matrix }=128 \times \\
128, \mathrm{FOV}=240 \mathrm{~cm}^{2}, \text { slice thickness } / \text { interval }=6 / 2 \mathrm{~mm} \\
\text { four slices evaluated }\end{array}$ & $\begin{array}{l}\text { FA reduced in all WM regions in SZs } \\
\text { n,bilaterally compared with controls. } \\
\text { There were no significant } \\
\text { correlations between FA and PANSS } \\
\text { scores. Correlations between FA and } \\
\text { antipsychotic medication dose were } \\
\text { calculated for } n=10 \text { SZs and FA of } \\
\text { left frontal WM was correlated } \\
\text { significantly with dosage of } \\
\text { antipsychotic medication }\end{array}$ \\
\hline $\begin{array}{l}\text { Kubicki et al. (2003) } \\
\text { [54] }\end{array}$ & $\begin{array}{l}\text { FA and area } \\
\text { were assessed } \\
\text { in the cingulate } \\
\text { bundle in SZs } \\
\text { and in controls }\end{array}$ & $\begin{array}{l}16 \text { chronic male SZs } \\
\text { (mean age } 43 \text { ), and } 18 \\
\text { emale controls (mean age } \\
43 \text { ) }\end{array}$ & $\begin{array}{l}1.5 \mathrm{~T} \mathrm{MRI} \text { scanner, coronals, six directions, FOV }=220 \\
\times 165 \mathrm{~mm}^{2} \text {, matrix }=128 \times 128(256 \times 256 \text { interpolated } \\
\text { eimage matrix }) \text {, slice thickness/interval }=4 / 1 \mathrm{~mm} \text {, total of } \\
31-35 \text { coronal slices covering entire brain }\end{array}$ & $\begin{array}{l}\text { Both SZs and controls showed a left } \\
\text { d> right asymmetry for CB on all } \\
\text { fmeasures. In addition, SZs showed } \\
\text { reduced mean area and lower mean } \\
\text { FA bilaterally, relative to controls. } \\
\text { Decreased diffusion in CB was also } \\
\text { associated with poorer performance } \\
\text { on the WCST, which is heavily } \\
\text { dependent upon intact } \\
\text { communication between prefrontal } \\
\text { and anterior cingulate gyrus }\end{array}$ \\
\hline
\end{tabular}


MR, magnetic resonance; FA, fractional anisotropy; WM, white matter; SZ, schizophrenia patient; FOV, field of view; CC, corpus callosum; NEX, number of excitations; MRI, magnetic resonance imaging; UF, uncinate fasiculus; CB, cingulum bundle; SZAFF, schizoaffective; STG, superior temporal gyrus; PHG, parahippocampal gyrus; PANSS, Positive and Negative Syndrome Scale; WCST, Wisconsin Card Sorting Test. 
Table 3

Postmortem white matter findings in schizophrenia

\begin{tabular}{|c|c|c|c|}
\hline Author & Study participants & Methods & Findings \\
\hline Eastwood and Harrison (2003) [62**] & \multicolumn{3}{|c|}{$\begin{array}{ll}12 \mathrm{SZs}(7 \mathrm{M} / 5 \mathrm{~F}, \text { mean age } 60), & \text { 14 Interstitial neurons of superficialDensity increased in superficial } \\
\text { controls }(6 \mathrm{M} / 8 \mathrm{~F}, \text { mean age 53) } & \begin{array}{l}\text { and deep temporal white matter temporal white matter, not } \\
\text { immunostained with the }\end{array} \\
\begin{array}{l}\text { neuronal marker NeuN, in-situ } \\
\text { hybridization }\end{array} & \begin{array}{l}\text { Reelin expression decreased in } \\
\text { both }\end{array}\end{array}$} \\
\hline Kirkpatrick et al. (1999) [63] & $\begin{array}{l}3 \text { deficit } \mathrm{SZs}(2 \mathrm{M} / 1 \mathrm{~F}, \text { mean age } \\
44), 4 \text { nondeficit } \mathrm{SZs}(3 \mathrm{M} / 1 \mathrm{~F}, \\
\text { mean age } 26), 5 \text { controls }(2 \mathrm{M} / 3 \mathrm{~F}, \\
\text { mean age } 29)\end{array}$ & $\begin{array}{l}\text { Interstitial neurons of the } \\
\text { dorsolateral prefrontal white } \\
\text { matter stained with anti- } \\
\text { microtubule-associated protein } \\
\text { MAP2 antibody }\end{array}$ & $\begin{array}{l}\text { Increased density of interstitial } \\
\text { neurons in deficit patients with } \\
\text { schizophrenia compared with } \\
\text { other groups }\end{array}$ \\
\hline Rioux et al. (2003) [64] & \multicolumn{3}{|c|}{$\begin{array}{l}15 \text { controls }(8 \mathrm{M} / 7 \mathrm{~F} \text {, mean age 74)anterior parahippocampal white deeper in the white matter in } \\
\text { matter stained with anti- } \\
\text { microtubule-associated protein }\end{array}$} \\
\hline Uranova et al. (2004) [65] & \multicolumn{3}{|c|}{$\begin{array}{l}15 \mathrm{SZs}(9 \mathrm{M} / 6 \mathrm{~F} \text {, mean age } 45), 15 \text { Oligodendroglial cell density in Decreased density of } \\
\text { controls }(9 \mathrm{M} / 6 \mathrm{~F}, \text { mean age } 42) \\
\begin{array}{ll}\text { layer VI of prefrontal cortex andoligodendrocytes in the cortex, } \\
\text { adjacent white matter }\end{array} \\
\begin{array}{l}\text { but not in the adjacent white } \\
\text { matter in schizophrenia }\end{array}\end{array}$} \\
\hline Hof et al. (2003) [66 & $\begin{array}{l}7 \mathrm{SZs}(3 \mathrm{M} / 4 \mathrm{~F}, \text { mean age } 77), 7 \\
\text { controls }(4 \mathrm{M} / 3 \mathrm{~F}, \text { mean age } 79)\end{array}$ & $\begin{array}{l}\text { Number, density and spatial } \\
\text { distribution of oligodendrocytes } \\
\text { in layer III and gyral white } \\
\text { matter of the superior frontal } \\
\text { gyrus }\end{array}$ & $\begin{array}{l}\text { Decreased number and density } \\
\text { sof oligodendrocytes, as well as } \\
\text { less clustered arrangement of } \\
\text { oligodendrocytes in white } \\
\text { matter in schizophrenia }\end{array}$ \\
\hline Flynn et al. (2003) [57**] & $\begin{array}{l}13 \mathrm{SZs}(6 \mathrm{M} / 7 \mathrm{~F}, \text { mean age } 48), 11 \\
\text { controls }(8 \mathrm{M} / 3 \mathrm{~F}, \text { mean age } 46)\end{array}$ & $\begin{array}{l}1 \text { Immunoreactivity of } \\
\text { oligodendrocyte-associated } \\
\text { proteins in schizophrenia in } \\
\text { anterior frontal cortex }\end{array}$ & $\begin{array}{l}\text { Decreased immunoreactivity in } \\
\text { two myelin-associated proteins } \\
\text { in schizophrenia }\end{array}$ \\
\hline Tkachev et al. (2003) [67] & $15 \mathrm{SZs}, 15$ controls & $\begin{array}{l}\text { Expression of oligodendrocyte } \\
\text { and myelin-related genes in } \\
\text { prefrontal cortex }\end{array}$ & $\begin{array}{l}\text { Reduction of the expression of } \\
\text { genes related to myelination } \\
\text { growth and differentiation, and } \\
\text { oligodendrocyte lineage, growth } \\
\text { and function in schizophrenia }\end{array}$ \\
\hline Aston et al. (2004) [68] & \multirow{2}{*}{\multicolumn{2}{|c|}{$\begin{array}{l}12 \mathrm{SZs}(7 \mathrm{M} / 5 \mathrm{~F} \text {, mean age } 45), 14 \text { Expression of myelin-related } \\
\text { controls }(10 \mathrm{M} / 4 \mathrm{~F} \text {, mean age } 49) \text { genes in middle temporal gyrus } \\
8 \text { male SZs (mean age 60), } 9 \text { maleNumber and length of brain } \\
\begin{array}{l}\text { controls (mean age 60) } \\
\text { nerve fibers calculated } \\
\text { stereotactically }\end{array}\end{array}$}} & $\begin{array}{l}\text { Decreased expression of } \\
\text { myelination-related genes }\end{array}$ \\
\hline Marner and Pakkenberg (2003) [69*] & & & $\begin{array}{l}\text { Total length of nerve fibers in } \\
\text { white matter not different } \\
\text { between groups in } \\
\text { schizophrenia }\end{array}$ \\
\hline
\end{tabular}

SZ, schizophrenia patient. 